\title{
Discovery of a novel Nrf2 inhibitor that induces apoptosis of human acute myeloid leukemia cells
}

\author{
JinFeng Zhang ${ }^{1,2}$, Le Su ${ }^{1}$, Qing $\mathrm{Ye}^{3}$, ShangLi Zhang ${ }^{1}$, HsiangFu Kung ${ }^{1,4}$, Fan Jiang ${ }^{3}$, \\ GuoSheng Jiang ${ }^{5}$, JunYing Miao ${ }^{1,3}$, BaoXiang Zhao ${ }^{6}$ \\ ${ }^{1}$ Shandong Provincial Key Laboratory of Animal Cells and Developmental Biology, School of Life Science, Shandong University, \\ Jinan 250100, China \\ ${ }^{2}$ School of Municipal and Environmental Engineering, Shandong Jianzhu University, Jinan 250101, China \\ ${ }^{3}$ Key Laboratory of Cardiovascular Remodeling and Function Research, Chinese Ministry of Education and Chinese Ministry \\ of Health, Qilu Hospital, Shandong University, Jinan, 250012, China \\ ${ }^{4}$ Institute of Pathology and Southwest Cancer Center, Third Military Medical University, Chongqing, 400038, China \\ ${ }^{5}$ Key Medical Laboratory for Tumor Immunology and Traditional Chinese Medicine Immunology, Key Laboratory for Rare and \\ Uncommon Diseases of Shandong, Institute of Basic Medicine, Shandong Academy of Medical Sciences, Jinan 250062, China \\ ${ }^{6}$ Institute of Organic Chemistry, School of Chemistry and Chemical Engineering, Shandong University, Jinan 250100, China \\ Correspondence to: JunYing Miao, email: miaojy@sdu.edu.cn \\ BaoXiang Zhao, email: bxzhao@sdu.edu.cn \\ GuoSheng Jiang, email: Jiangguosh@163.com
}

Keywords: pyrazolyl hydroxamic acid derivatives, Nrf2 inhibitors, acute myeloid leukemia, apoptosis, Bcl-2

Received: May 18, 2016

Accepted: November 30, 2016

Published: December 09, 2016

\section{ABSTRACT}

Nuclear factor-erythroid 2-related factor 2 ( Nrf2) is persistently activated in many human tumors including acute myeloid leukemia (AML). Therefore, inhibition of Nrf2 activity may be a promising target in leukemia therapy. Here, we used an antioxidant response element-luciferase reporter system to identify a novel pyrazolyl hydroxamic acid derivative, 1-(4-(tert-Butyl)benzyl)-3-(4-chlorophenyl)- $\mathrm{N}$-hydroxy-1H pyrazole5-carboxamide (4f), that inhibited Nrf2 activity. $4 \mathrm{f}$ had a profound growth-inhibitory effect on three AML cell lines, THP-1, HL-60 and U937, and a similar anti-growth effect in a chick embryo model. Moreover, flow cytometry of AML cells revealed increased apoptosis with $4 \mathrm{f}(10 \mu \mathrm{M})$ treatment for $48 \mathrm{~h}$. The protein levels of cleaved caspase-3 and cleaved poly (ADP-ribose) polymerase were enhanced in all three AML cell types. Furthermore, Nrf2 protein level was downregulated by $4 \mathrm{f}$. Upregulation of Nrf2 by tert-butylhydroquinone (tBHQ) or Nrf2 overexpression could ameliorate $4 \mathrm{f}$-induced growth inhibition and apoptosis. Treatment with $4 \mathrm{f}$ reduced both B-cell lymphoma-2 (Bcl-2) expression and $\mathrm{Bcl}-2 / \mathrm{Bcl}-2-$ associated $\mathrm{X}$ protein (Bax) ratio, which indicated that $4 \mathrm{f}$ induced apoptosis, at least in part, via mitochondrial-dependent signaling. Therefore, as an Nrf2 inhibitor, the pyrazolyl hydroxamic acid derivative $4 \mathrm{f}$ may be a promising agent in AML therapy.

\section{INTRODUCTION}

Acute myeloid leukemia (AML) is the most common leukemia occurring in adults. The disease is due to abnormal differentiation of hematopoietic stem cells and is characterized by the accumulation of abnormal blasts in bone marrow [1]. From global gene profiling, approximately $50 \%$ of adults with AML feature chromosomal abnormalities, contributing to leukemia pathogenesis and heterogeneity $[2,3]$. Some promising agents such as gemtuzumab ozogamicin (GO) [4], sorafenib [5] and AMG-330 [6] have been approved in preclinical and clinical trials. However, treatment-related mortality and drug resistance are the main obstacles that restrict their application. Therefore, new therapies and promising drug candidates are needed to overcome the inadequacy of traditional cytotoxic agents.

Nuclear factor-erythroid 2-related factor 2 (NFE2L2, also called Nrf2) is a ubiquitously expressed transcriptional factor that belongs to the cap'n'collar 
family of basic leucine-zipper (b-ZIP) proteins [7]. The Kelch-like ECH-associated protein 1 (Keap1)-Nrf2 system represents a major regulatory mechanism and controls adaptive responses to multiple stressors. Under normal homeostatic circumstances, Nrf2 binds with Keap1 for degradation to maintain a low level [8]. In response to reactive oxygen species (ROS) or electrophilic stress, Nrf2 dissociates with Keap1 and binds to antioxidant response element (ARE) localized in the promoter region, thereby inducing the expression of a wide array of genes [9] including heme oxygenase-1 (HO-1) [10], NAD(P) $\mathrm{H}$ :quinone oxidoreductase 1 [11], catalytic subunit of glutamate cysteine ligase (GCLC) [12] and multi-drug resistance gene family [13]. The precise mechanism of Nrf2 in tumorigenesis has been actively investigated in vitro and in vivo because of the pivotal role of $\mathrm{Nrf} 2$ as a defense mechanism against various cellular stressors in cancer cells [14-16]. Increasing evidence reveals that highly constitutive activation of Nrf2 is associated with increased risk of various human tumors [17, 18]. Nrf2 siRNA knockdown or inhibition of Nrf2 activity by some chemicals renders cancer cells susceptible to apoptosis $[19,20]$. To date, several Nrf2 inhibitors, such as alltrans retinoic acid, other retinoic acid receptor $\alpha$ agonists [21], luteolin [22] and brusatol [23], have been identified.
Therefore, the discovery and development of more Nrf2 inhibitors would be an attractive therapeutic strategy to improve AML therapy.

In this work, we used an ARE-luciferase reporter approach to screen a series of pyrazolyl hydroxamic acid derivatives and identified a novel compound, 1-(4-(tertButyl)benzyl)-3-(4-chlorophenyl)-N-hydroxy-1H pyrazole5-carboxamide (4f), that inhibited Nrf2 activity, for an anti-growth effect on AML cells.

\section{RESULTS}

\section{Effect of the pyrazolyl hydroxamic acid derivatives (4a-4l) on Nrf2 activity}

A cell-based Nrf2-luciferase system can be used to monitor an immediate response for high-throughput screening of Nrf2 modulators [24]. We used HeLa cells, which stably express functional ARE-driven reporter genes, to screen a series of pyrazolyl hydroxamic acid derivatives (4a-41, Figure 1A). Luciferase activity was decreased with compound $4 \mathrm{f}$ or $4 \mathrm{~g}(10 \mu \mathrm{M})$ incubation for $12 \mathrm{~h}$ but was maintained in other treated groups (Figure 1B), which suggests that both $4 \mathrm{f}$ and $4 \mathrm{~g}$ inhibited Nrf2-ARE signaling. To confirm the effect on Nrf2
A
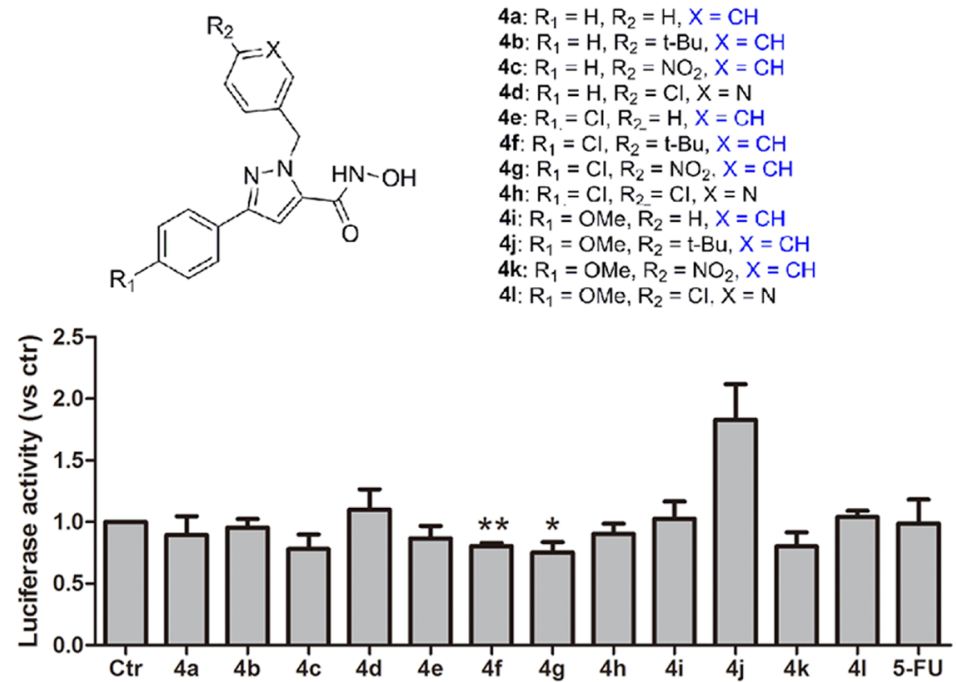

4b: $R_{1}=H, R_{2}=t-B u, X=C H$

4c: $R_{1}=H, R_{2}=N_{2}, X=C H$

4 d: $R_{1}=H, R_{2}=C l, X=N$

4e: $R_{1}=\mathrm{Cl}, \mathrm{R}_{2_{-}}=\mathrm{H}, \mathrm{X}=\mathrm{CH}$

4f: $\mathrm{R}_{1}=\mathrm{Cl}, \mathrm{R}_{2}=\mathrm{t}-\mathrm{Bu}, \mathrm{X}=\mathrm{CH}$

4h: $R_{1}=\mathrm{Cl}, \mathrm{R}_{2}=\mathrm{Cl}, \mathrm{X}=\mathrm{N}$

4i: $R_{1}=O M R_{1} R_{2}=H X$

4j: $R_{1}=O M e, R_{2}=t-B u, X=C H$

4k: $R_{1}=O M e, R_{2}=\mathrm{NO}_{2}, X=\mathrm{CH}$

4I: $R_{1}=O M e, R_{2}=C l . X=N$

D
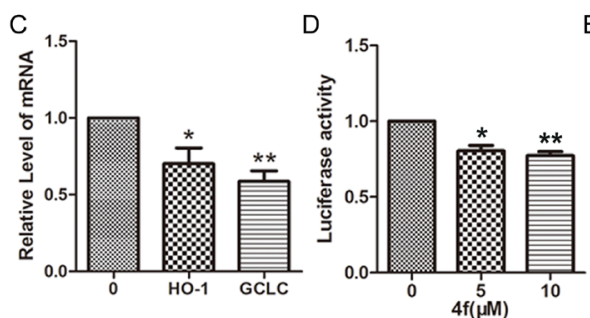

$\mathrm{E}$

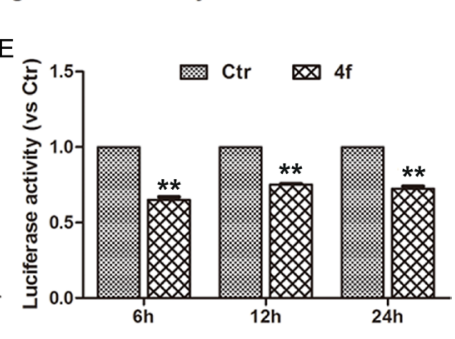

Figure 1: Effect of pyrazolyl hydroxamic acid derivatives (4a-4l) on Nrf2 activity. (A) Chemical structures of pyrazolyl hydroxamic acids (4a-4l). (B) HeLa cells stably transfected with an ARE-luciferase reporter gene were incubated with compounds 4a-4l at $10 \mu \mathrm{M}$ for $12 \mathrm{~h}$. Luciferase activity was determined by luciferase assay, with control activity set to 1 . (C) The expression of two target genes of Nrf2, HO-1 and GCLC, in treated cells was examined by RT-PCR. (D-E) The relative level of luciferase activity in HeLa cells incubated with $4 \mathrm{f}$ at 5 and $10 \mu \mathrm{M}$ for $12 \mathrm{~h}$ or at $10 \mu \mathrm{M}$ for 6,12 and $24 \mathrm{~h}$. Data are mean \pm SEM. $* p<0.05, * * p<0.01$ vs Ctr (untreated group), $n=3$. 
Table 1: The $\mathrm{IC}_{50}$ values $(\mu \mathrm{M}, 48 \mathrm{~h})$ of the compounds $4 \mathrm{f}$ and $4 \mathrm{~g}$ in three acute myeloid leukemia cell types

\begin{tabular}{|c|c|c|c|}
\hline Compound & $4 \mathrm{f}$ & $4 \mathrm{~g}$ & 5-FU \\
\hline THP-1 & 5.33 & 8.23 & 5.18 \\
\hline HL-60 & 8.94 & 9.58 & 7.78 \\
\hline U937 & 8.98 & 9.79 & 18.10 \\
\hline
\end{tabular}

inhibition, we examined the mRNA levels of $\mathrm{HO}-\mathrm{I}$ and $G C L C$, two downstream target genes of Nrf2. As expected, mRNA levels of $H O-1$ and $G C L C$ were downregulated with $4 \mathrm{f}(10 \mu \mathrm{M})$ treatment for $12 \mathrm{~h}$ (Figure 1C). Furthermore, both 5 and $10 \mu \mathrm{M} 4 \mathrm{f}$ decreased luciferase activity at $12 \mathrm{~h}$ as compared with controls (Figure 1D). A similar effect was observed with $4 \mathrm{f}(10 \mu \mathrm{M})$ treatment for different times (Figure 1E). Therefore, the results revealed that compound $4 \mathrm{f}$ inhibited $\mathrm{Nrf2}$ activation.

\section{Effect of compounds $4 f$ and $4 \mathrm{~g}$ on the growth of three AML cell types}

Next, we used CCK-8 assay to investigate the effect of $4 \mathrm{f}$ and $4 \mathrm{~g}$ on the growth of three human AML cell lines, THP-1, HL-60 and U937. 4f or 4g inhibited growth of the three AML cell types at 5, 10 or $20 \mu \mathrm{M}$ for $48 \mathrm{~h}$ (Figure 2). With increasing concentration, the cytotoxicity was enhanced accordingly for all tested cells. The growthinhibitory ratio was even up to $80-90 \%$ at $20 \mu \mathrm{M}$. The half maximal inhibitory concentrations $\left(\mathrm{IC}_{50}\right)$ for the three AML cell types ranged from 5 to $10 \mu \mathrm{M}$ (Table 1). According to Nrf2 activity inhibition and cell viability, we chose $4 \mathrm{f}$ for further investigation.

\section{Compound $4 \mathrm{f}$ induces apoptosis of three AML cells in vitro}

We performed flow cytometry to clarify whether apoptosis or necrosis was responsible for the $4 \mathrm{f}$ antileukemia effect. $4 \mathrm{f}$ at $10 \mu \mathrm{M}$ markedly increased the proportion of apoptotic THP-1 cells (61.55\%, Figure 3A). For HL-60 and U937 cells, approximately $46.8 \%$ of HL60 cells and $61.1 \%$ of U937 cells were at early and late apoptosis stages. In 4f-treated AML cells (THP-1, HL60 and U937), the percentages of early apoptotic cells were $10.45 \%, 14.7 \%$ and $23.3 \%$, respectively. However, there are a few necrotic cells in HL-60 and U937 cells as compared with controls (Figure 3B-3C). Therefore, apoptosis may be the main mode of cell death in the three AML cell types.

Subsequently, we detected the activation of caspase-3 and poly (ADP-ribose) polymerase (PARP), the key proteins in apoptosis. The results showed a significant increase in level of cleaved caspase-3 (C-caspase 3 ) and PARP (C-PARP) with $10 \mu \mathrm{M} 4 \mathrm{f}$ treatment (Figure 3D-3F).
Thus, $4 \mathrm{f}$ triggered caspase-dependent apoptotic signaling in AML cells.

\section{Compound 4f inhibits tumor growth via apoptosis in vivo}

The chorioallantoic membrane (CAM) of chick eggs is a well-established model for rapidly and inexpensively screening new anti-cancer drugs in many human cancers including blood malignancies $[25,26]$. Therefore, we seeded cells on CAMs of chicken eggs and evaluated the tumor-growth-inhibitory effect of compound $4 \mathrm{f}$ treatment in vivo. The tumor size in CAMs was smaller with $4 \mathrm{f}$ than control treatment, with inhibitory rate approximately $40 \%$ (Figure 4A). Furthermore, to detect apoptotic cells, tumor sections were labeled by terminal deoxy-nucleotidyl transferase-mediated digoxigenin-dUTP nick-end labeling (TUNEL). 4f-treated tumor sections showed increased number of apoptotic cells as compared with controls (Figure 4B). Hence, compound 4f suppressed the growth of tumors in a chick embryo model, with apoptosis mainly accounting for reduced cell numbers.

\section{Nrf2 is decreased by compound $4 \mathrm{f}$ in three AML cells}

Despite compound $4 \mathrm{f}$ inhibited Nrf2 activity in ARE-luciferase reporter transfected HeLa cells, we examined whether Nrf2 protein level was altered in the three AML cell lines. As shown in Figure 5, 4f treatment led to the reduction of Nrf2 expression in THP-1 cells. Similarly, Nrf2 protein level was decreased in 4f-treated HL-60 and U937 cells.

\section{Upregulation of $\mathrm{Nrf} 2$ ameliorates $4 \mathrm{f}$-induced growth inhibition and apoptosis}

Based on the above findings, we wondered whether growth inhibition and apoptosis induced by $4 \mathrm{f}$ were related to inhibiting Nrf2 expression. It has been documented that the antioxidant $\mathrm{tBHQ}$ is an Nrf2 activator promoting Nrf2 stability and inducing the expression of Nrf2-related genes [30-32]. Thus, we used tBHQ to clarify the role of Nrf2 in the effect of $4 \mathrm{f}$. The addition of tBHQ increased THP-1 cell viability in the presence of $4 \mathrm{f}$ (Figure 6A). Meanwhile, Nrf2 protein level was upregulated, and C-caspase 3 and 
C-PARP level were downregulated (Figure 6B-6E). 4f plus tBHQ resulted in cell viability decreased as compared with tBHQ alone (Figure 6A), which was accompanied by decreased Nrf2 and enhanced expression of C-caspase 3 and C-PARP (Figure 6B-6E). Thus, activation of Nrf2 by tBHQ could ameliorate $4 \mathrm{f}$-induced growth inhibition and apoptosis.

Furthermore, exogenous transfection of an Nrf2 plasmid in THP-1 cells was performed by electrotransfection followed by $4 \mathrm{f}$ treatment. Overexpression of Nrf2 significantly caused Nrf2 protein level upregulation (Supplementary Figure S1). Cell viability assay revealed that Nrf2 overexpression promoted cell growth and decreased the sensitivity to $4 \mathrm{f}$ treatment (Figure 6F). Both $\mathrm{C}$-caspase 3 and C-PARP protein levels were decreased when compared with the vector groups (Figure 6G-6J).
Treatment with $4 \mathrm{f}$ reversed cell viability, as well as the protein levels of Nrf2, C-caspase 3 and C-PARP in Nrf2overexpressed cells. Therefore, these results demonstrate that growth inhibition and apoptosis by $4 \mathrm{f}$ are related to Nrf2 reduction.

\section{B-cell lymphoma-2 (Bcl-2) and Bcl-2-associated $X$ protein $(B a x)$ are involved in the apoptotic signaling induced by $4 \mathrm{f}$}

To explore the mechanism by which compound $4 \mathrm{f}$ induced apoptosis, we examined Bcl-2 and Bax, two members of Bcl-2 family involved in mitochondriadependent apoptotic signaling [27]. Bax protein level was increased and that of $\mathrm{Bcl}-2$ protein level and ratio of $\mathrm{Bcl}-$ 2/Bax were decreased when THP-1 cells were exposed to
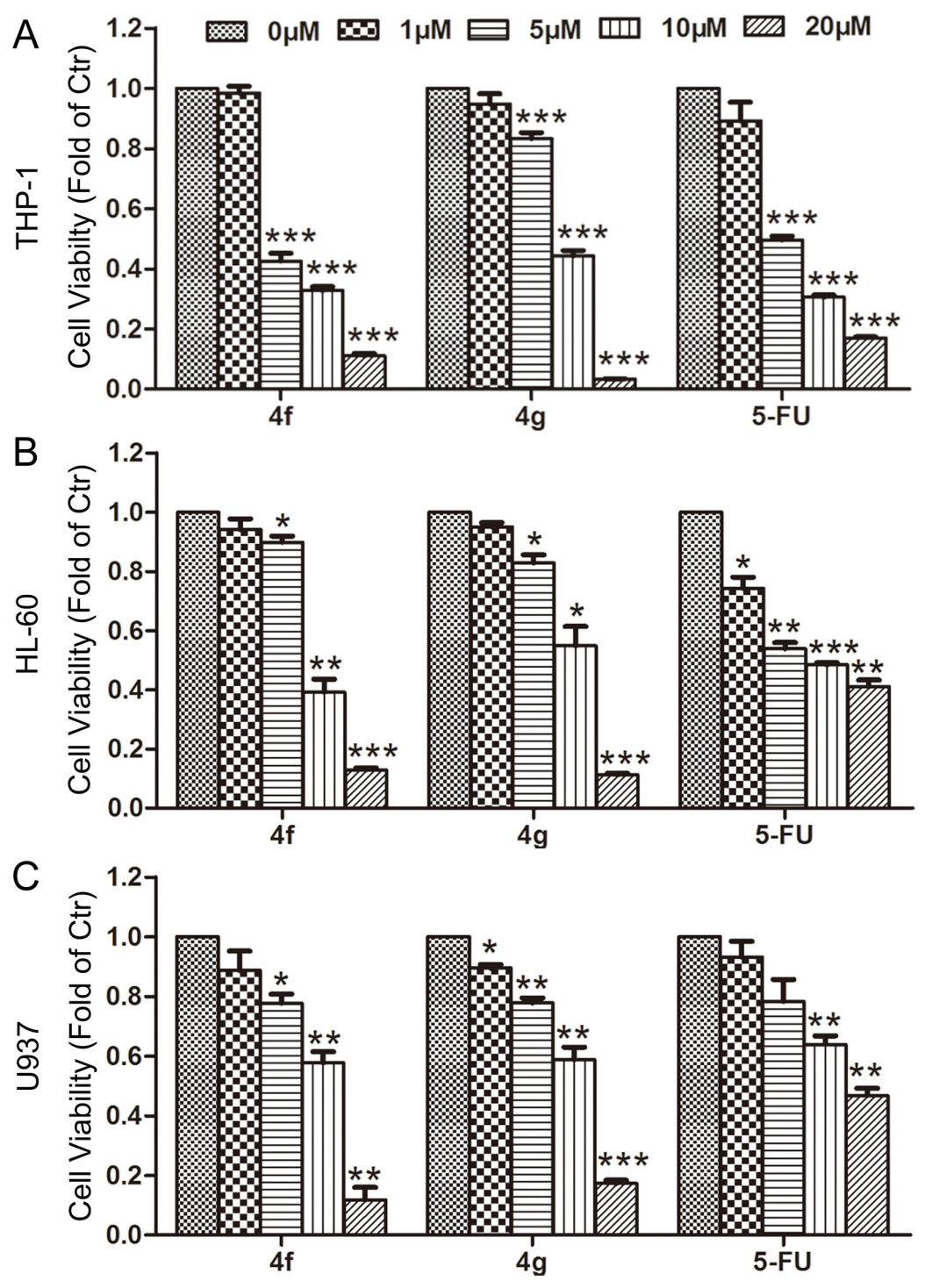

Figure 2: Effect of compounds 4 f and $4 \mathrm{~g}$ on the growth of three AML cell types. THP-1, HL-60 and U937 cells were exposed to compound $4 \mathrm{f}$ or $4 \mathrm{~g}$ at $1,5,10$ and $20 \mu \mathrm{M}$ for $48 \mathrm{~h}$. Cell viability was measured by CCK-8 assay. 5 -FU was used as a positive control. Viability of cells in controls was set to 1 . Data are mean \pm SEM. ${ }^{*} p<0.05, * * p<0.01, * * * p<0.001$ vs Ctr (untreated group), $n=3$. 

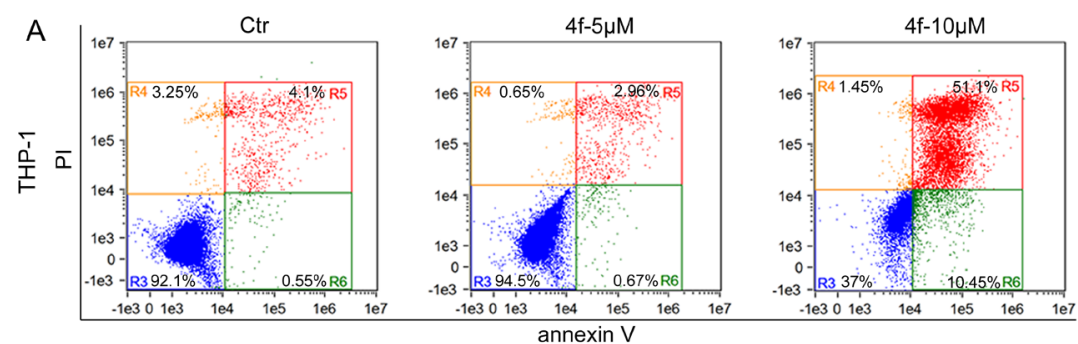

B
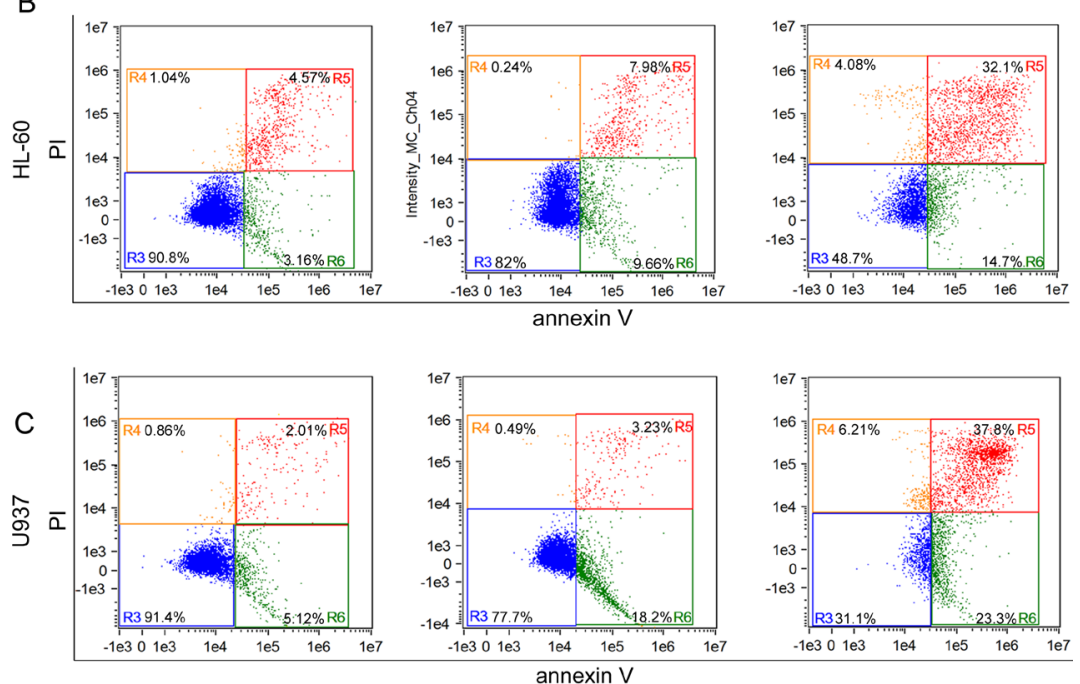

D
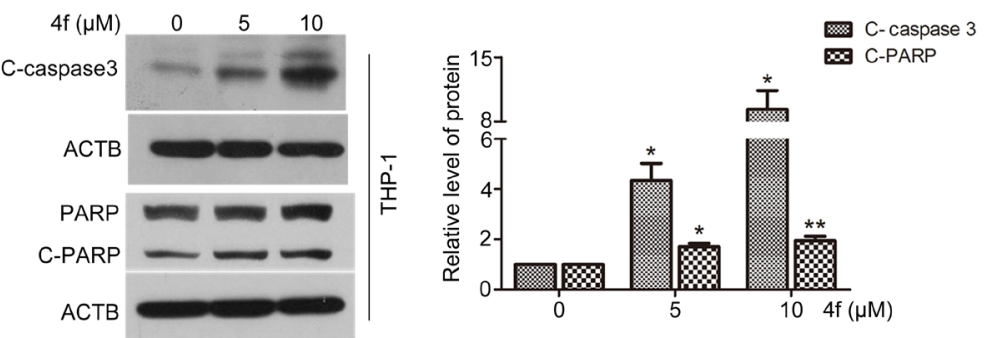

E

$\begin{array}{llll}4 f(\mu M) & 0 & 5 & 10\end{array}$
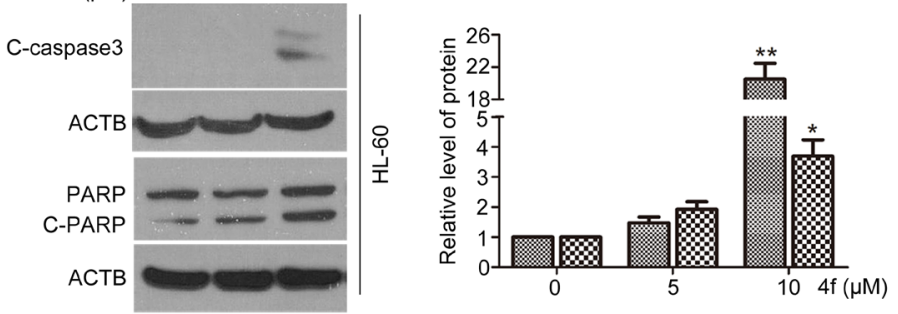

F
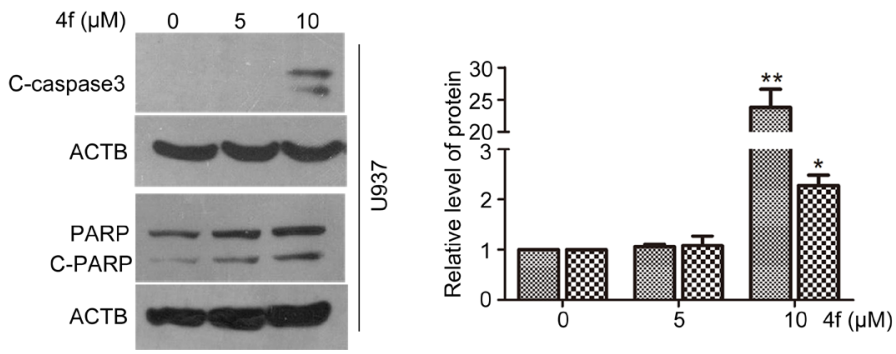

Figure 3: Compound $4 \mathrm{f}$ induces apoptosis in AML cells in vitro. Cells were treated with the compound $4 \mathrm{f}(5$ or $10 \mu \mathrm{M})$ for 48 h. (A-C) Apoptosis was determined by flow cytometry. (D-F) The protein levels of cleaved caspase 3 (C-caspase 3 ) and cleaved PARP (C-PARP) were detected by western blotting. $\beta$-actin (ACTB) was a loading control. The protein levels were normalized to ACTB. One representative experiment in 3 is shown. Data are mean $\pm \mathrm{SEM} . * p<0.05, * * p<0.01$ vs Ctr (untreated group). 
4f at 5 and $10 \mu \mathrm{M}$ for $48 \mathrm{~h}$ (Figure $7 \mathrm{~A}-7 \mathrm{C}$ ), with similar effects in the two other AML cell types (Figure 7D-7I). Thus, involvement of Bcl-2 and Bax in mitochondriadependent apoptotic signaling may contribute to 4f-induced apoptotic cell death.

\section{DISCUSSION}

In the present work, we identified a novel pyrazolyl hydroxamic acid derivative, $4 \mathrm{f}$, with potential inhibition of Nrf2, which is persistently activated in many human
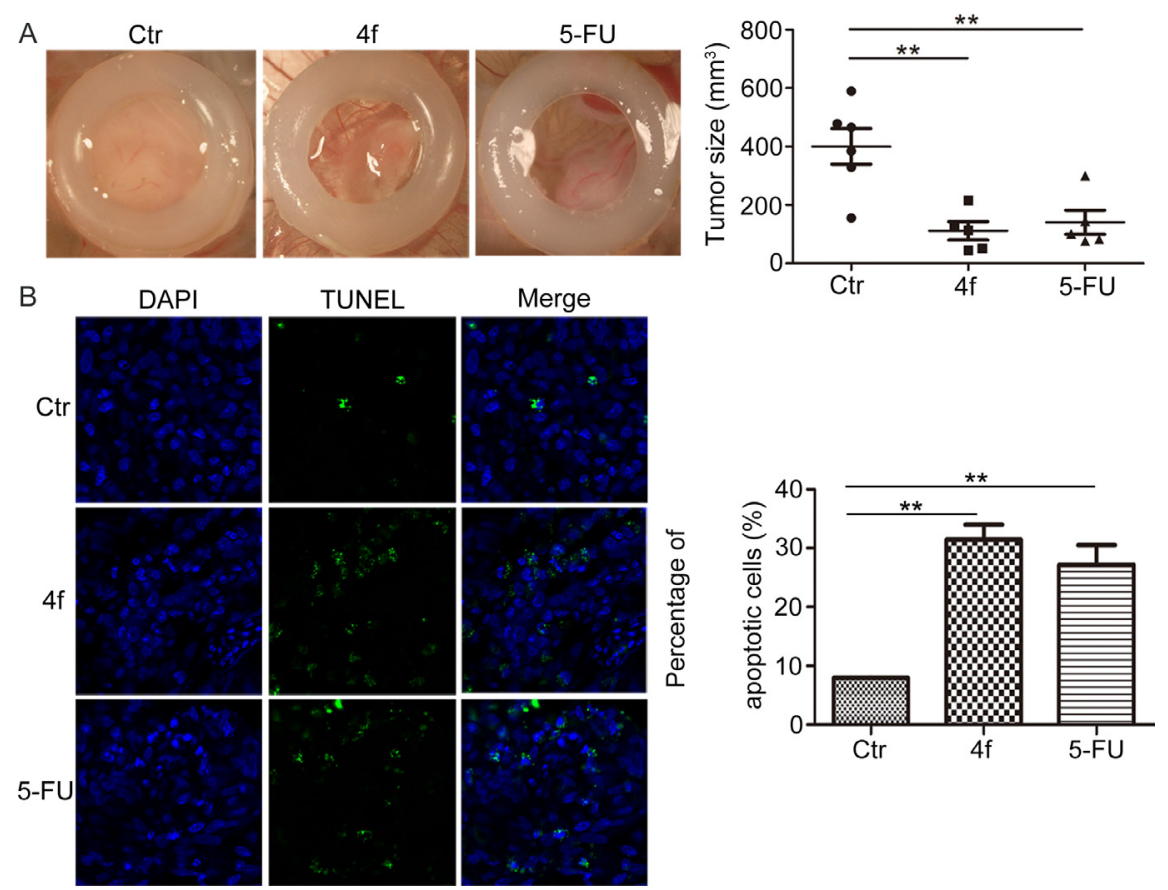

Figure 4: Compound $4 \mathrm{f}$ inhibits tumor growth via apoptosis in vivo. (A) THP-1 cells were seeded onto the CAMs of chicken eggs to evaluate the tumor-growth-inhibitory effect of $4 \mathrm{f}$ in vivo. 5-FU was a positive control. The tumor size was calculated by densitometry analysis. Horizontal lines are means and whiskers are SEM. Data represent 1 sample. (B) TUNEL assay of sections of tumors (magnification $100 \times)$. Data are mean \pm SEM. $* * p<0.01$ vs Ctr.

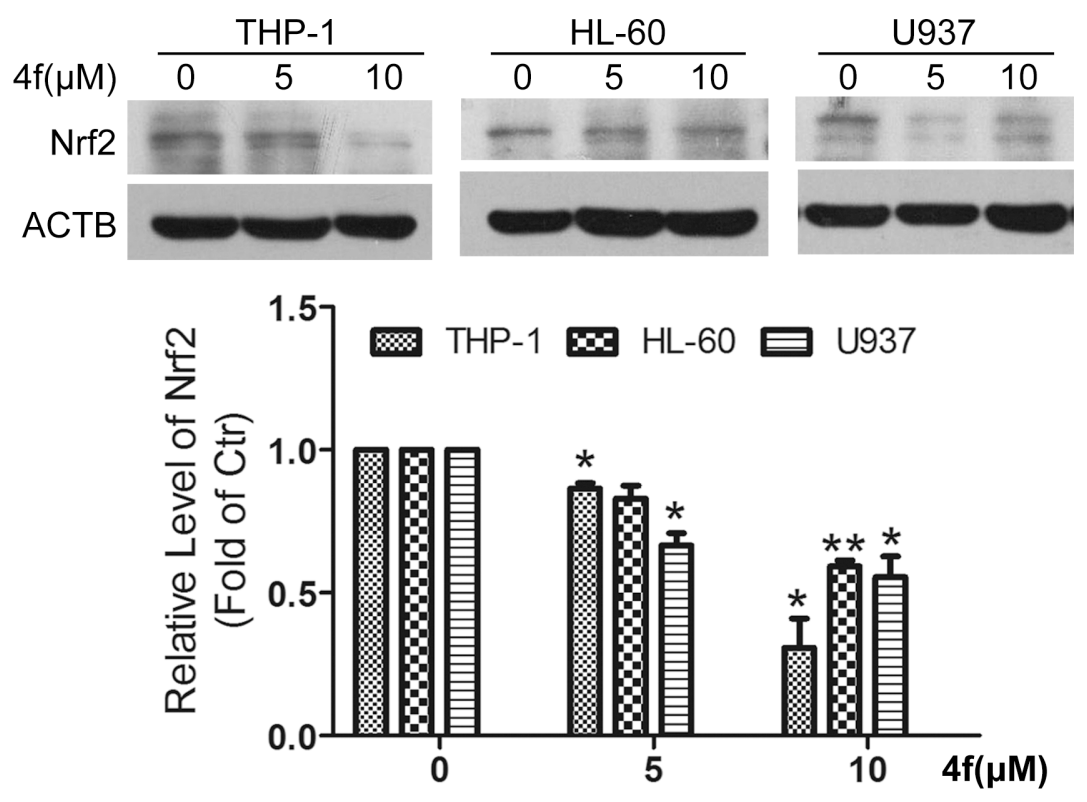

Figure 5: Nrf2 is decreased by compound $4 \mathrm{f}$ in three AML cells. All three AML cells were exposed to $4 \mathrm{f}(5$ and $10 \mu \mathrm{M})$ for $48 \mathrm{~h}$, and then Nrf2 protein level was determined by western blot. The protein level of Nrf2 was normalized to ACTB (as a loading control). One representative experiment in 3 is shown. Data are mean \pm SEM. ${ }^{*} p<0.05, * * p<0.01$ vs Ctr (untreated group), $n=3$. 

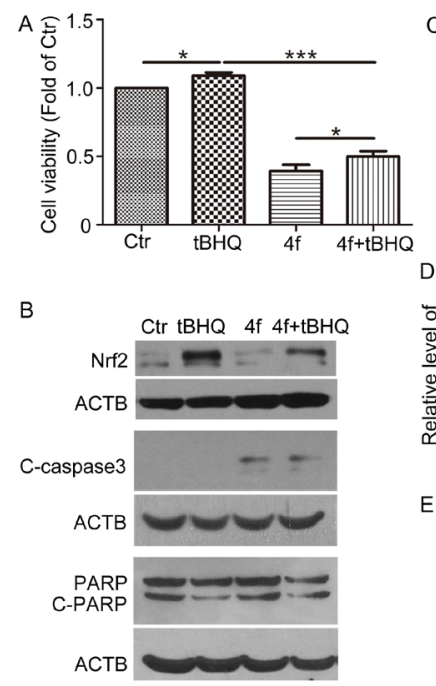

C
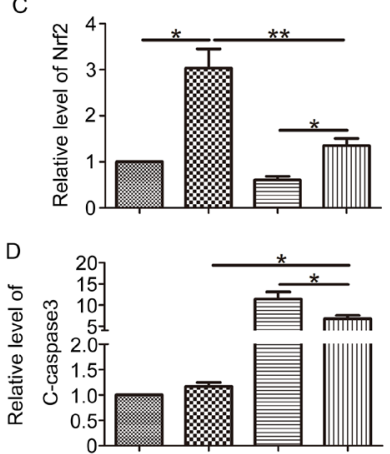

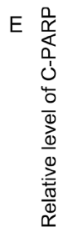

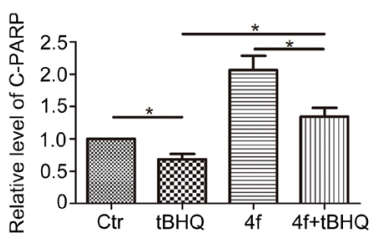

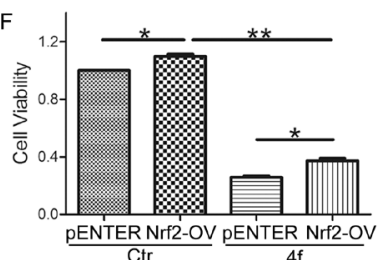

G

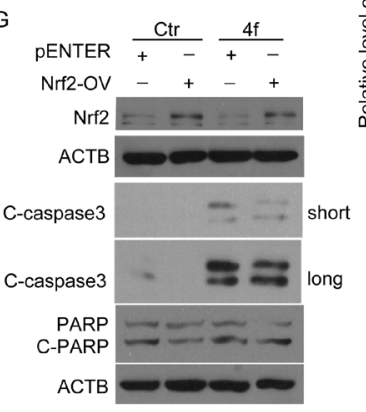

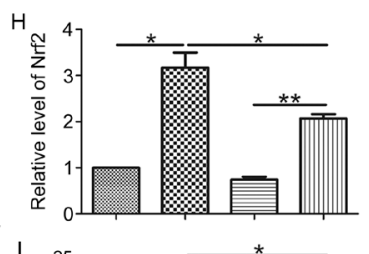
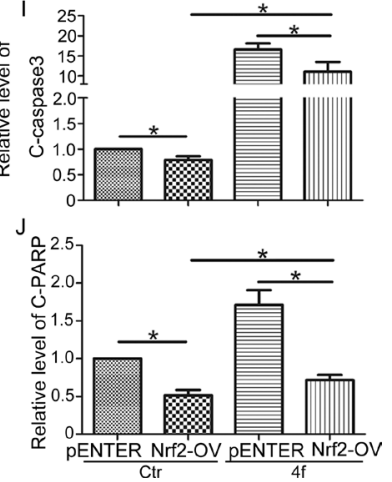

Figure 6: Upregulation of Nrf2 ameliorates 4 f-induced growth inhibition and apoptosis. After exposure to tBHQ ( $50 \mu \mathrm{M})$, $4 \mathrm{f}(10 \mu \mathrm{M})$ or tBHQ plus $4 \mathrm{f}$ for $48 \mathrm{~h}$, THP-1 cell viability was measured by CCK8 assay (A). The protein levels of Nrf2, C-caspase 3 and C-PARP were detected by western blot analysis (B-E). After transfection with an Nrf2 expression plasmid (Nrf2-OV) or the corresponding control vector (pENTER) for $24 \mathrm{~h}$, THP-1 cells were incubated with $4 \mathrm{f}$ for another $48 \mathrm{~h}$. Cell viability was determined by CCK8 assay (F). Nrf2, C-caspase 3 and C-PARP were analyzed by western blot $(\mathbf{G}-\mathbf{J})$. Viability of cells in controls was set to 1 . The protein levels were normalized to ACTB (a loading control). One representative experiment in 3 is shown. Data are mean \pm SEM. ${ }^{*} p<0.05,{ }^{* *} p<0.01$, $* * * p<0.001, n=3$.
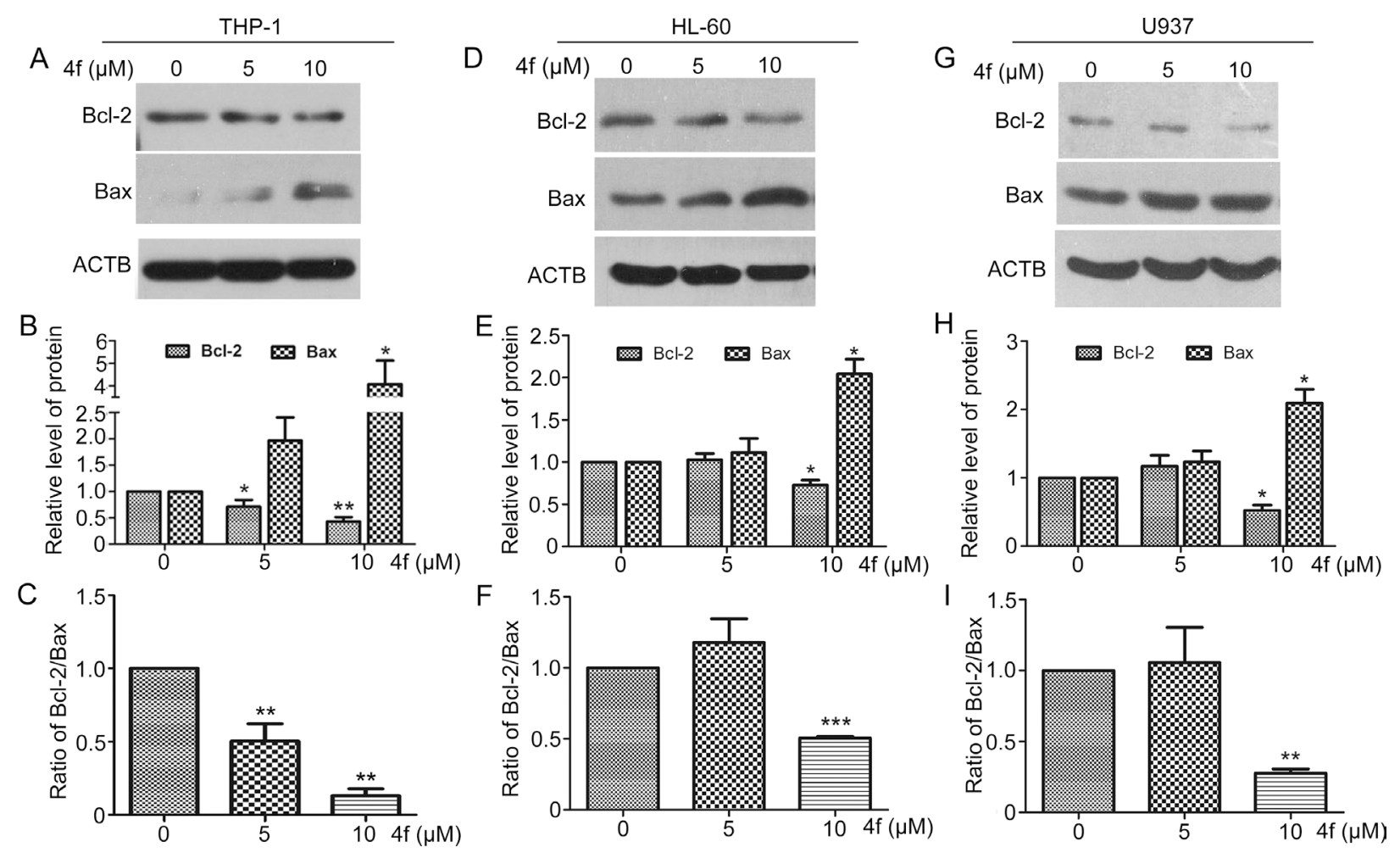

Figure 7: Bcl-2 and Bax are involved in the apoptotic signaling induced by $4 \mathbf{f}$. After incubation with $4 \mathrm{f}$ at 5 or $10 \mu \mathrm{M}$ for 48 h, Bcl-2 and Bax protein levels were examined by western blot analysis (A-C) for THP-1 cells, (D-F) for HL-60 cells and (G-I) for U937 cells). One representative experiment in 3 is shown. ACTB was a loading control. Data are mean \pm SEM. ${ }^{*} p<0.05, * * p<0.01, * * * p<$ 0.001 vs Ctr (untreated group). 
tumors including AML. 4f showed effective anti-leukemia activity and triggered apoptosis via mitochondriadependent signaling, which suggests its potential application in AML therapy.

In this study, a luciferase reporter system revealed that among pyrazolyl hydroxamic acid derivatives, compounds $4 \mathrm{f}$ and $4 \mathrm{~g}$ inhibited $\mathrm{Nrf} 2$ activity (Figure 1B), which was further confirmed by HO-1 and GCLC mRNA downregulation (Figure 1C). Moreover, we found a decreased Nrf2 protein level in 4f-treated AML cells (Figure 5). In contrast to isoniazid, with high ARE activity inhibition $\left(\mathrm{IC}_{50} 10 \mathrm{mM}\right)$ [28], the concentration of $4 \mathrm{f}$ or $4 \mathrm{~g}$ in suppressing Nrf2 is smaller. Further study revealed that the two compounds at higher concentration remarkably inhibited growth of THP-1, HL-60 and U937 AML cells (Figure 2). 4f had better anti-growth effect than $4 \mathrm{~g}$, and the $\mathrm{IC}_{50}$ value for $4 \mathrm{f}$ was smaller in THP-1 than HL-60 and U937 cells (Table 1). In addition, Nrf2 activation by $\mathrm{tBHQ}$ or Nrf2 overexpression could reverse $4 \mathrm{f}$-induced THP-1 cell viability reduction and apoptosis (Figure 6A). Therefore, compound 4f inhibits AML cell growth, which is associated with Nrf2 suppression. Consistent with our results, a recent study showed that silencing of Nrf2 in THP-1 cells sensitized the cells to cytotoxicity by multiple agents [29]. Additionally, Nrf2 activation was found to protect AML cells against $\mathrm{As}_{2} \mathrm{O}_{3}$ or bortezomib-induced apoptosis [29, 30]. The evidence has implied more effective growth inhibition of cancer cells when combining the compounds with Nrf2 inhibitors, such as $4 \mathrm{f}$.

ROS levels are higher in cancer cells than normal cells. Human tumors show persistent activation of an Nrf2-mediated response in defense against oxidative stress $[18,31]$. Nrf2 activation and ROS levels feature a negative loop, in that persistent Nrf2 inhibition leads to intracellular ROS accumulation. Excessive ROS would lead to irreversible biomolecule oxidization, mitochondrial proper function impairment and cell death [32]. In the current work, there was a significant increase in apoptotic cells after exposure to $4 \mathrm{f}$ in a dose-dependent manner, which was accompanied by $\mathrm{C}$-caspase 3 and C-PARP protein levels upregulated (Figure 3). Additionally, 4f-treated tumor sections showed increased number of apoptotic cells (Figure 4B). It should be noted that the proportion of late apoptotic and necrotic cells was higher than that of early apoptotic cells (Figure 3A-3C), suggesting that it may be better to use $4 \mathrm{f}$ at a lower dose in AML treatment. In a recent study by our laboratory, apoptosis was not triggered in 4f-treated A549 cells [33], which implies that the difference in cell death induced by $4 \mathrm{f}$ largely depends on cell type. We also found that cell cycle progression was arrested at the S phase by 4f in THP-1, HL-60 and U937 cells (Supplementary Figure S2). Hence, apoptosis and cell cycle arrest are mainly responsible for the growthinhibitory effect of $4 \mathrm{f}$ in the three AML cells.

The CAM system has long been used to study the growth and spread of mammalian tumors
$[25,34]$, as well as the angiogenesis and anti-angiogenesis potential $[35,36]$. In this study, 4 f not only suppressed the growth of THP-1 xenografts, but also blocked blood vessel development in an in vivo gelatin sponge assay (Supplementary Figure S3A). In agreement with the results, $4 \mathrm{f}(1,5,10$ and $20 \mu \mathrm{M})$ had a dose-dependent growthinhibitory effect on human umbilical vein endothelial cells (HUVECs) and SV40 T-antigen immortalized murine endothelial cells (MS1) (Supplementary Figure $\mathrm{S} 3 \mathrm{~B}$ and S3C). Therefore, we preliminarily ascertained that compound $4 \mathrm{f}$ inhibited angiogenesis. However, the detailed mechanism(s) requires further studies.

The $\mathrm{Bcl}-2 / \mathrm{Bax}$ ratio is considered an indicator of mitochondrial permeability [37, 38]. Increased Bcl-2 inhibits cell apoptosis in response to many chemotherapeutic agents [39, 40]. Recently, a study pointed out that Nrf2 deletion was associated with mitochondrial permeability, dysfunction and increasing apoptosis in murine embryonic fibroblasts [41]. Here, we found both $\mathrm{Bcl}-2$ protein level and $\mathrm{Bcl}-2 / \mathrm{Bax}$ ratio decreased during 4f-induced apoptosis (Figure 7), indicating that the normal function of mitochondria was disturbed. The direct relationship between Nrf2 and Bcl-2 expression was identified, in which $\mathrm{Nrf} 2$ directly bound to an ARE in the promoter region of $\mathrm{Bcl}-2$ gene to upregulate $\mathrm{Bcl}-2$ expression and increase the survival of cancer cells [14]. Consistent with this notion, our results illustrated an association between $\mathrm{Nrf} 2$ and Bcl-2 because both Nrf2 activity and $\mathrm{Bcl}-2 \mathrm{mRNA}$ expression were decreased with 4f treatment (Figure 1B-1E and Supplementary Figure S4). Therefore, Nrf2 inhibition by $4 \mathrm{f}$ may lead to apoptosis, at least in part, by mitochondrial-dependent signaling.

Taken together, in the present work, we found that a novel Nrf2 inhibitor, 4f, had a profound growth-inhibitory effect on three AML cell types (THP-1, HL-60 and U937). After suppressing Nrf2 and Bcl-2 expression, $4 \mathrm{f}$ triggered apoptosis via mitochondrial-dependent apoptotic signaling (Figure 8). Therefore, as an Nrf2 inhibitor, $4 \mathrm{f}$ is a promising lead compound that may have application in advanced AML treatment. Nonetheless, how $4 \mathrm{f}$ inhibits Nrf2 remains for further investigation.

\section{MATERIALS AND METHODS}

\section{Synthesis of pyrazolyl hydroxamic acids (4a-4l)}

The detailed procedure for the synthesis and structures of pyrazolyl hydroxamic acids (4a-4l) (Figure 1A) were described in our previous study [33].

\section{Reagents}

RPMI-1640 and DMEM (with high glucose) medium powder were from Gibco (Carlsbad, CA, USA). Fetal bovine serum (FBS) was from Hyclone (USA). The CCK-8 kit was from Dojindo Laboratories (Kumamoto, Japan). The FITC/Annexin V apoptosis detection kit 
with propidium iodide (640914) was from BioLegend (San Diego, CA, USA). Kits for TUNEL assay (In Situ Apoptotic Detection) (G3250) and luciferase assay (E1500) were from Promega (Madison, WI). TRIzol reagent (T9424) was from Sigma-Aldrich (St. Louis, MO). PrimeScript RT Master Mix (RR047A) was from Takara (Shiga, Japan). The QuantiTect SYBR Green PCR kit (204143) was from QIAGEN (Germany). Lysis buffer (P0013) and the bicinchonininc acid kit (BCA, P0011) were from Beyotime (Shanghai, China). Antibodies for PARP (9542S), cleaved caspase-3 (9661) and $\beta$-actin (A5441) were from Cell Signaling Technology (Danvers, MA, USA). Antibodies for Nrf2 (16396-1AP), Bcl-2 (12789-1-AP) and Bax (50599-2-Ig) were from Proteintech (Chicago, IL, USA). Horseradish peroxidase (HRP)-conjugated secondary antibodies were from Santa Cruz Biotechnology (Santa Cruz, CA, USA). tBHQ ( $\geq 97.0 \%$ ) was from Sigma-Aldrich. Dimethyl sulfoxide (DMSO) was from Beijing Solaris Science and Technology Company (Beijing, China). All compounds were dissolved in DMSO at $100 \mathrm{mM}$ and diluted into the indicated concentrations in culture medium before use, and the final concentration of DMSO (v/v) was $<0.1 \%$.

\section{Cell culture}

Human acute monocytic leukemia cell lines THP-1, U937 and human promyelomonocytic leukemia cell line HL-60 were grown in RPMI-1640 medium containing $10 \% \quad(\mathrm{v} / \mathrm{v})$ FBS supplemented with streptomycin $(100 \mu \mathrm{g} / \mathrm{mL})$ and penicillin $(100 \mathrm{U} / \mathrm{mL})$. HeLa cells (human cervical cancer cell line) stably transfected Nrf2responsive reporter plasmid (pGL4-3 $\times$ ARE) were a kind gift from Prof. Fan Jiang and were grown in DMEM media with high glucose. Cells were cultured at $37^{\circ} \mathrm{C}$ in a humidified atmosphere of $5 \% \mathrm{CO}_{2}$. Cells were plated in the indicated dishes for $24 \mathrm{~h}$ before treatment with compounds.

\section{Luciferase assay}

HeLa cells stably expressing an Nrf2-responsive reporter plasmid (pGL4-3 $\times$ ARE) were seeded in 96-well plates at $4 \times 10^{4} / \mathrm{ml}$ and cultured overnight, then incubated with the pyrazolyl hydroxamic acid derivatives at the indicated concentrations and times. After cell lysis buffer was added and collected, luciferase activity was examined by use

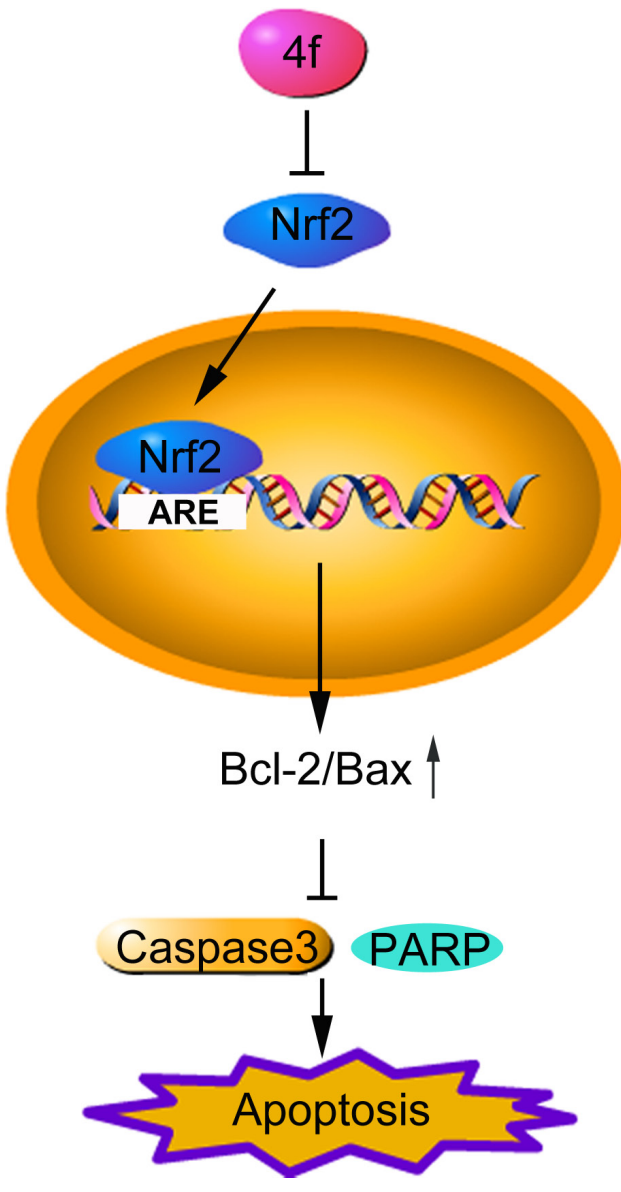

Figure 8: The schematic diagram of compound $4 \mathrm{f}$-induced apoptosis by inhibiting Nrf2 in AML cells. Compound $4 \mathrm{f}$ inhibits Nrf2 and its downstream gene expression, then triggers apoptosis via upregulating Bcl-2/Bax ratio and downregulating cleaved caspase 3 and cleaved PARP. Therefore, 4f has a profound anti-growth effect on three AML cell types (THP-1, HL-60 and U937). 
of the luciferase assay system. The final luciferase activity was normalized to cell viability assessed by MTT assay.

\section{Cell viability assay}

Cell viability was assessed by use of the CCK- 8 kit according to the manufacturer's instructions. Briefly, THP-1, HL-60 and U937 cells were seeded in 96-well plates before exposure to compounds $4 a-41(0,1,5,10$ and $20 \mu \mathrm{M}$ ) or 5-fluorouracil (5-FU, as positive) for $48 \mathrm{~h}$. WST-8 solution $(10 \mu \mathrm{L})$ was added to plates for further incubation. At $2 \mathrm{~h}$ later, the absorbance at wavelength 450 $\mathrm{nm}$ was measured by using the Tecan Infinite 200 PRO microplate spectrophotometer (Tecan Austria $\mathrm{GmbH}$ ). Cell viability was calculated and normalized to the value for control cells.

\section{Flow cytometry}

After adherent and detached cells were harvested and washed with PBS twice, cells were suspended with binding buffer $(100 \mu \mathrm{L})$ and stained with FITC/annexin V $(8 \mu \mathrm{L})$ and PI $(5 \mu \mathrm{L})$ for $30 \mathrm{~min}$ at $4{ }^{\circ} \mathrm{C}$. Then, cells were suspended with binding buffer $(50 \mu \mathrm{L})$ and examined by flow cytometry (Amnis ImageStream Marksims II, USA). Data were analyzed by using IDEAS image analysis software.

\section{Overexpression of Nrf2 in THP-1 cells}

Cells were collected into the electroporation cuvettes (4 mm, Bio-Rad, USA) at a density of $1 \times 10^{7} /$ $\mathrm{ml}$ before transfected with a pENTER-Nrf2 expression plasmid or the corresponding control vector (Vigene Biosciences, USA). $36 \mathrm{~h}$ later, the transfection efficiency was determined by western blot.

\section{RT-PCR analysis}

Cells were incubated with or without the compound $4 \mathrm{f}$ for the indicated times. Total RNA was isolated by the TRIzol reagent method and RNA content was determined by measuring $\mathrm{OD}_{260}$. cDNA was synthesized by using the PrimeScript RT reagent kit with gDNA Eraser. RTPCR involved use of the QuantiTect SYBR Green PCR kit with $2 \mu \mathrm{L}$ cDNA template, $10 \mu \mathrm{L}$ of $2 \times$ SYBR Green, $0.4 \mu \mathrm{L}$ forward primers, $0.4 \mu \mathrm{L}$ reverse primers and $7.2 \mu \mathrm{L}$ distilled water. RT-PCR cycling was at $95^{\circ} \mathrm{C}$ for $5 \mathrm{~min}, 95^{\circ} \mathrm{C} 30 \mathrm{~s}, 56^{\circ} \mathrm{C} 30 \mathrm{~s}$ and $72{ }^{\circ} \mathrm{C} 30 \mathrm{~s}$ for 40 cycles. Relative expression of target genes was analyzed by the $2^{-\Delta \Delta C t}$ method and normalized to $\beta$-actin level. The primer sequences are in Supplementary Table S1.

\section{Western blot analysis}

After cells were lysed in lysis buffer and protein concentrations were determined by BCA protein assay, equal amounts of whole protein lysates $(20-50 \mu \mathrm{g})$ were separated by $12-15 \%$ SDS-PAGE and electrophoretically transferred to polyvinylidene fluoride membranes (Millipore, Schwalbach, Germany). The membranes were blocked with $5 \%$ non-fat dry milk in Tris buffer saline containing $0.5 \%$ Tween 20 (TBST) and incubated with primary antibodies at $4{ }^{\circ} \mathrm{C}$ overnight, then HRP-conjugated secondary antibodies for $1 \mathrm{~h}$ at room temperature before two additional washes with PBS. Proteins were detected by use of an ECL detection kit (Thermo Fisher Scientific, USA, 35060). Image J (US National Institutes of Health, USA) was used to quantify protein bands on X-ray film.

\section{Engraftment of THP-1 cells in chicken embryos}

Fertile chicken eggs were incubated with turning at $37.5^{\circ} \mathrm{C}$ and $60 \%$ humidity. After a small aperture was cut in the eggshell, cells at $(1-10) \times 10^{6}$ were suspended in $20 \mu \mathrm{L}$ RPMI 1640 medium and layered onto the large CAM of eggs at embryonic day 7 to 9 (E7-9). Egg shells were sealed with gas-permeable tape, then eggs were randomized to three groups and incubated for another 7 days with injection of PBS (negative control), $4 \mathrm{f}$ $(50 \mu \mathrm{M})$ or 5 -FU (positive group) every $48 \mathrm{~h}$. Embryos were removed on E14-16 and killed by rapid decapitation. CAMs were separated from eggs, fixed with $4 \%$ paraformaldehyde for $30 \mathrm{~min}$ and photographed by use of a stereomicroscope (Japan). Data were quantified by using Image J. Tumor size was based on tumor volume calculation: length $\times$ width $\times$ width $\times 0.5$.

\section{Terminal deoxynucleotidyl transferase-mediated dUTP nick-end labeling (TUNEL)}

Excised tumor tissue was embedded in optimal cutting temperature (OCT) medium (Tissue-Tek, 4583) and cut into cryosections of $7 \mu \mathrm{m}$. Apoptotic cells in tumor sections were detected by TUNEL assay according to the manufacturer's instructions. Briefly, cryosections were fixed with $4 \%$ paraformaldehyde for $30 \mathrm{~min}$ and incubated with $0.2 \%$ Triton $\mathrm{X}-100$ for $5 \mathrm{~min}$, then with TUNEL reaction solution for $1 \mathrm{~h}$ at $37^{\circ} \mathrm{C}$ before SSC solution was added to terminate the reaction. After washes with PBS three times, sections were stained with DAPI for 5 min and observed by confocal microscopy (Carl Zeiss, Germany).

\section{Statistical analysis}

All data were presented as mean \pm SEM from least three independent experiments. Data analysis involved Student's $t$ test with GraphPad Prism 5.0. Differences were considered statistically significant at $p<0.05$.

\section{ACKNOWLEDGMENTS}

This work was supported by the National Natural Science Foundation of China (No. 91313303, 31570834, 
31270877 and 81573467), the Major Project of Science and Technology of Shandong Province (NO. 2015ZDJS04001 and 2015ZDJS04003), the Natural Science Foundation of Shandong Province (NO. ZR2015HM014), the Twelfth Five-Year National Science and Technology Support Program (2013BAI07B02), the Project for Laureate of Taishan Scholar (NO. ts201511075) and Shandong Excellent Young Scientist Award Fund (No. BS2013SW001).

\section{CONFLICTS OF INTEREST}

The authors declare no conflicts of interest.

\section{REFERENCES}

1. Tenen DG. Disruption of differentiation in human cancer: AML shows the way. Nature reviews Cancer. 2003; 3:89-101.

2. Meyer SC, Levine RL. Translational implications of somatic genomics in acute myeloid leukaemia. The Lancet Oncology. 2014; 15:e382-394.

3. Grimwade D, Ivey A, Huntly BJ. Molecular landscape of acute myeloid leukemia in younger adults and its clinical relevance. Blood. 2016; 127:29-41.

4. Castaigne S, Pautas C, Terre C, Raffoux E, Bordessoule D, Bastie JN, Legrand O, Thomas X, Turlure P, Reman O, de Revel T, Gastaud L, de Gunzburg N, et al. Effect of gemtuzumab ozogamicin on survival of adult patients with denovo acute myeloid leukaemia (ALFA-0701): a randomised, open-label, phase 3 study. Lancet. 2012; 379:1508-1516.

5. Ravandi F, Cortes JE, Jones D, Faderl S, Garcia-Manero G, Konopleva MY, O'Brien S, Estrov Z, Borthakur G, Thomas D, Pierce SR, Brandt M, Byrd A, et al. Phase I/II study of combination therapy with sorafenib, idarubicin, and cytarabine in younger patients with acute myeloid leukemia. Journal of clinical oncology. 2010; 28:1856-1862.

6. Krupka C, Kufer P, Kischel R, Zugmaier G, Bogeholz J, Kohnke T, Lichtenegger FS, Schneider S, Metzeler KH, Fiegl M, Spiekermann K, Baeuerle PA, Hiddemann W, et al. CD33 target validation and sustained depletion of AML blasts in long-term cultures by the bispecific T-cellengaging antibody AMG 330. Blood. 2014; 123:356-365.

7. Moi P, Chan K, Asunis I, Cao A, Kan YW. Isolation of NF-E2-related factor 2 (Nrf2), a NF-E2-like basic leucine zipper transcriptional activator that binds to the tandem NF-E2/AP1 repeat of the beta-globin locus control region. Proceedings of the National Academy of Sciences of the United States of America. 1994; 91:9926-9930.

8. Taguchi K, Motohashi H, Yamamoto M. Molecular mechanisms of the Keap1-Nrf2 pathway in stress response and cancer evolution. Genes to cells : devoted to molecular \& cellular mechanisms. 2011; 16:123-140.

9. Kaspar JW, Niture SK, Jaiswal AK. Nrf2:INrf2 (Keap1) signaling in oxidative stress. Free radical biology \& medicine. 2009; 47:1304-1309.
10. Alam J, Stewart D, Touchard C, Boinapally S, Choi AM, Cook JL. Nrf2, a Cap'n'Collar transcription factor, regulates induction of the heme oxygenase-1 gene. The Journal of biological chemistry. 1999; 274:26071-26078.

11. Itoh K, Chiba T, Takahashi S, Ishii T, Igarashi K, Katoh Y, Oyake T, Hayashi N, Satoh K, Hatayama I, Yamamoto M, Nabeshima Y. An Nrf2/small Maf heterodimer mediates the induction of phase II detoxifying enzyme genes through antioxidant response elements. Biochemical and biophysical research communications. 1997; 236:313-322.

12. Li M, Chiu JF, Kelsen A, Lu SC, Fukagawa NK. Identification and characterization of an Nrf2-mediated ARE upstream of the rat glutamate cysteine ligase catalytic subunit gene (GCLC). Journal of cellular biochemistry. 2009; 107:944-954.

13. Vollrath V, Wielandt AM, Iruretagoyena M, Chianale J. Role of Nrf2 in the regulation of the Mrp2 (ABCC2) gene. Biochemical Journal. 2006; 395:599-609.

14. Niture SK, Jaiswal AK. Nrf2 protein up-regulates antiapoptotic protein Bcl-2 and prevents cellular apoptosis. The Journal of biological chemistry. 2012; 287:9873-9886.

15. Ramos-Gomez M, Kwak MK, Dolan PM, Itoh K, Yamamoto M, Talalay P, Kensler TW. Sensitivity to carcinogenesis is increased and chemoprotective efficacy of enzyme inducers is lost in nrf2 transcription factor-deficient mice. Proceedings of the National Academy of Sciences of the United States of America. 2001; 98:3410-3415.

16. Syu JP, Chi JT, Kung HN. Nrf2 is the key to chemotherapy resistance in MCF7 breast cancer cells under hypoxia. Oncotarget. 2016; 7:14659-14672. doi: 10.18632/ oncotarget. 7406 .

17. Singh A, Misra V, Thimmulappa RK, Lee H, Ames S, Hoque MO, Herman JG, Baylin SB, Sidransky D, Gabrielson E, Brock MV, Biswal S. Dysfunctional KEAP1NRF2 interaction in non-small-cell lung cancer. PLoS medicine. 2006; 3:1865-1876.

18. Shibata T, Ohta T, Tong KI, Kokubu A, Odogawa R, Tsuta K, Asamura H, Yamamoto M, Hirohashi S. Cancer related mutations in NRF2 impair its recognition by Keap1Cul3 E3 ligase and promote malignancy. Proceedings of the National Academy of Sciences of the United States of America. 2008; 105:13568-13573.

19. Arlt A, Sebens S, Krebs S, Geismann C, Grossmann M, Kruse ML, Schreiber S, Schafer H. Inhibition of the Nrf2 transcription factor by the alkaloid trigonelline renders pancreatic cancer cells more susceptible to apoptosis through decreased proteasomal gene expression and proteasome activity. Oncogene. 2013; 32:4825-4835.

20. Arlt A, Bauer I, Schafmayer C, Tepel J, Muerkoster SS, Brosch M, Roder C, Kalthoff H, Hampe J, Moyer MP, Folsch UR, Schafer H. Increased proteasome subunit protein expression and proteasome activity in colon cancer relate to an enhanced activation of nuclear factor E2-related factor 2 (Nrf2). Oncogene. 2009; 28:3983-3996. 
21. Wang XJ, Hayes JD, Henderson CJ, Wolf CR. Identification of retinoic acid as an inhibitor of transcription factor Nrf2 through activation of retinoic acid receptor alpha. Proceedings of the National Academy of Sciences of the United States of America. 2007; 104:19589-19594.

22. Tang XW, Wang HY, Fan LF, Wu XY, Xin A, Ren HY, Wang XJ. Luteolin inhibits Nrf2 leading to negative regulation of the Nrf2/ARE pathway and sensitization of human lung carcinoma A549 cells to therapeutic drugs. Free radical biology \& medicine. 2011; 50:1599-1609.

23. Ren DM, Villeneuve NF, Jiang T, Wu TD, Lau A, Toppin HA, Zhang DD. Brusatol enhances the efficacy of chemotherapy by inhibiting the Nrf2-mediated defense mechanism. Proceedings of the National Academy of Sciences of the United States of America. 2011; 108:1433-1438.

24. Smirnova NA, Haskew-Layton RE, Basso M, Hushpulian DM, Payappilly JB, Speer RE, Ahn YH, Rakhman I, Cole PA, Pinto JT, Ratan RR, Gazaryan IG. Development of Neh2-luciferase reporter and its application for high throughput screening and real-time monitoring of Nrf2 activators. Chemistry \& biology. 2011; 18:752-765.

25. Taizi M, Deutsch VR, Leitner A, Ohana A, Goldstein RS. A novel and rapid in vivo system for testing therapeutics on human leukemias. Experimental hematology. 2006; 34:1698-1708.

26. Farnoushi Y, Cipok M, Kay S, Jan H, Ohana A, Naparstek E, Goldstein RS, Deutsch VR. Rapid in vivo testing of drug response in multiple myeloma made possible by xenograft to turkey embryos. British journal of cancer. 2011; 105:1708-1718.

27. Susin SA, Lorenzo HK, Zamzami N, Marzo I, Snow BE, Brothers GM, Mangion J, Jacotot E, Costantini P, Loeffler M, Larochette N, Goodlett DR, Aebersold R, et al. Molecular characterization of mitochondrial apoptosis-inducing factor. Nature. 1999; 397:441-446.

28. Chen Y, Xue P, Hou Y, Zhang H, Zheng H, Zhou T, Qu W, Teng W, Zhang Q, Andersen ME, Pi J. Isoniazid suppresses antioxidant response element activities and impairs adipogenesis in mouse and human preadipocytes. Toxicology and applied pharmacology. 2013; 273:435-441.

29. Peng H, Wang H, Xue P, Hou Y, Dong J, Zhou T, Qu W, Peng S, Li J, Carmichael PL, Nelson B, Clewell R, Zhang Q, et al. Suppression of NRF2-ARE activity sensitizes chemotherapeutic agent-induced cytotoxicity in human acute monocytic leukemia cells. Toxicology and applied pharmacology. 2016; 292:1-7.
30. Rushworth SA, Bowles KM, MacEwan DJ. High basal nuclear levels of Nrf2 in acute myeloid leukemia reduces sensitivity to proteasome inhibitors. Cancer research. 2011; 71:1999-2009.

31. Hu Y, Ju Y, Lin D, Wang Z, Huang Y, Zhang S, Wu C, Jiao S. Mutation of the Nrf2 gene in non-small cell lung cancer. Molecular biology reports. 2012; 39:4743-4747.

32. Murphy MP. How mitochondria produce reactive oxygen species. The Biochemical journal. 2009; 417:1-13.

33. Zhang JF, Li M, Miao JY, Zhao BX. Biological activities of novel pyrazolyl hydroxamic acid derivatives against human lung cancer cell line A549. European journal of medicinal chemistry. 2014; 83:516-525.

34. Steiner N, Ribatti D, Willenbacher W, Johrer K, Kern J, Marinaccio C, Aracil M, Garcia-Fernandez LF, Gastl G, Untergasser G, Gunsilius E. Marine compounds inhibit growth of multiple myeloma in vitro and in vivo. Oncotarget. 2015; 6:8200-8209. doi: 10.18632/oncotarget.3362.

35. Ribatti D, Vacca A, Roncali L, Dammacco F. The chick embryo chorioallantoic membrane as a model for in vivo research on angiogenesis. The International journal of developmental biology. 1996; 40:1189-1197.

36. Hazel SJ. A novel early chorioallantoic membrane assay demonstrates quantitative and qualitative changes caused by antiangiogenic substances. The Journal of laboratory and clinical medicine. 2003; 141:217-228.

37. Mignotte B, Vayssiere JL. Mitochondria and apoptosis. European journal of biochemistry / FEBS. 1998; 252:1-15.

38. Youle RJ, Strasser A. The BCL-2 protein family: opposing activities that mediate cell death. Nature reviews Molecular cell biology. 2008; 9:47-59.

39. Raffo AJ, Perlman H, Chen MW, Day ML, Streitman JS, Buttyan R. Overexpression of bcl-2 protects prostate cancer cells from apoptosis in vitro and confers resistance to androgen depletion in vivo. Cancer research. 1995; 55:4438-4445.

40. Fulda S, Meyer E, Debatin KM. Inhibition of TRAILinduced apoptosis by $\mathrm{Bcl}-2$ overexpression. Oncogene. 2002; 21:2283-2294.

41. Ariza J, Gonzalez-Reyes JA, Jodar L, Diaz-Ruiz A, de Cabo R, Villalba JM. Mitochondrial permeabilization without caspase activation mediates the increase of basal apoptosis in cells lacking Nrf2. Free radical biology \& medicine. 2016; 95:82-95. 